\title{
As reformas educacionais na década de 1920 no Brasil e as políticas de formação de professores primários
}

The educational reforms in the 1920s in Brazil and the primary teacher training policies

Las reformas educacionales en la década de 1920 en Brasil y las políticas de formación de profesores primarios

Sueli Menezes Pereira

Universidade Federal de Santa Maria (Brasil)

http://orcid.org/0000-0003-0831-7494

http://lattes.cnpq.br/3883536502592508

sueli.ufsm@gmail.com

\section{RESUMO}

O texto trata das reformas educacionais dos Estados de São Paulo, Minas Gerais e Rio Grande do Sul na década de 1920, tendo como foco as políticas de formação de professores primários no Brasil. Resultado de uma pesquisa histórica de caráter teórico-documental, tendo na legislação a fonte primária de análise, este trabalho tem por objetivo evidenciar os interesses mascarados do capital nas políticas de formação de professores primários na época. Os resultados evidenciam o conflito entre o novo e o existente, onde aí se identifica o foco de reflexão que nos permite compreender, nas questões educacionais, o papel do professor primário, a partir das tensões que se inserem na sua formação em nossa realidade.

Palavras chave: Reformas educacionais da década de 1920. Políticas de formação de professores primários. Teoria e prática. 


\begin{abstract}
The text is about the educational reformation in São Paulo, Minas Gerais and Rio Grande do Sul States in the decade of 1920, having as focus the politics of education of elementary school teachers in Brazil. It is the result of a historical search of theoretical-documental character, based in legislation as primary source of analyses, this work has as objective to evidence the masked interests of capital in politics of education of elementary teachers in that time. The results evince the conflict between the new and existing, where is identify the focus of reflection that allow to comprehend, in education aspect, the role of elementary teacher, through the stress that are insert in the education in the reality.
\end{abstract}

Keywords: Educational reforms of the 1920s. Primary teacher education policies. Theory and practice.

\title{
RESUMEN
}

El artículo trata de las reformas de la educación en las provincias de San Pablo, Minas Gerais y Rio Grande del Sur en la década de 1920. Tiene como objeto central las políticas de formación de maestros de enseñanza primaria en Brasil. Resulta de una investigación histórica de carácter teórico y documental, que tiene en la legislación la principal fuente de análisis, el presente trabajo tiene como objetivo poner en relieve los intereses enmascarados del capital en las políticas de formación de maestros en el periodo. Los resultados muestran el conflicto entre lo nuevo y lo existente donde si identifica el reflejo del enfoque que nos permite comprender, en materia de educación, el papel de la maestra primaria en las tensiones que se incluyen en su formación en nuestra realidad.

Palabras clave: Reformas educativas de la década de 1920. Políticas de formación de profesores primarios. Teoría y práctica. 


\section{Introdução}

Este texto trata da formação de professores primários no Brasil, assunto que tem gerado embates e proposições, colocando-se especial atenção na formação de professores nas reformas educativas ao longo de nossa história. Por ser pauta de discussões, sempre que se fala em educação pública, obrigatória e de qualidade, indica que a escola primária é referência para o sistema educacional dada a sua imprescindibilidade, questão que provoca reflexões no contexto da realidade brasileira de modo a evidenciar que o desenvolvimento das políticas educativas, na lógica do capital, tem colocado no professor a maior parcela de responsabilidade em sua implementação.

Isto se compreende com Hill (2003, p. 27), quando enfatiza que a escola, para o capital, através de seus profissionais, deverá estar voltada para "o desenvolvimento e força da única mercadoria sobre a qual depende o sistema capitalista: a força de trabalho" (grifos do autor).

Os professores são os guardiões da qualidade da força de trabalho! Este potencial, este poder latente que têm os professores é a razão pela qual os representantes do Estado perdem o sono preocupando-se sobre seu papel em assegurar que os futuros trabalhadores sejam entregues aos locais de trabalho pelo capital nacional e que disponham da mais alta qualidade possível. (HILL, 2003, p. 27 - grifo do autor).

Partindo dessas premissas, o propósito deste estudo é revelar os interesses mascarados do capital nas políticas de formação de professores que se traduzem na legislação, o que indica, em uma perspectiva marxista que "o modo de produção da vida material condiciona o processo de vida social, política e intelectual. Não é a consciência dos homens que determina o seu ser; ao contrário, é o seu ser social que determina sua consciência”. (MARX, 2008, p. 47).

Nesta ótica, longe de interpretações do senso comum que evidenciam a aparência e encobrem a essência dos fenômenos, analisa as políticas de formação de professores primários na década de 1920, fase que é marcada pelo processo de urbanização e industrialização sob o impulso da acumulação capitalista. Neste período, como defende Caio Prado Junior (2012, p. 2012), "a acumulação capitalista se faz efetivamente à custa de um empobrecimento relativo da massa da população, sobretudo das classes trabalhadoras, e um acréscimo de exploração do trabalho. Será esta a verdadeira origem dos novos capitais formados".

Na realidade, a década de 1920 assiste uma crise do modelo econômico brasileiro agroexportador. A Velha República é abalada não por ser "incompatível com os anseios de democracia", mas por suas bases políticas - construídas na política do café-com-leite não terem mais condições de preservar a hegemonia São Paulo-Minas Gerais.

$\mathrm{Na}$ mesma conjuntura, a onda de imigrantes e as mudanças geradas pela industrialização localizada, a imprensa operária... as reformas católicas afetaram as estruturas sociais brasileiras... e a República Velha não conseguiu reverter ou controlar os conflitos sociais que se arrastavam desde o fim da monarquia.

Afirmava-se, naquele momento uma aceleração no processo de industrialização, pois o próprio "complexo exportador cafeeiro engendrou o capital-dinheiro disponível para transformação em capital industrial" (MELLO, 1982, p.147), ampliando-se a busca da educação como a solução para os problemas nacionais, o que reflete na educação primária e normal.

A Igreja Católica, também inserida nessa disputa, reorganiza sua política de centralização e presença nas esferas educativas, principalmente, quando os partidários da industrialização, aspirando a recomposição do poder político, que se mantinha absoluto nas mãos do latifúndio, começam a perceber a educação como um importante fator de mudanças. 
Neste processo, no bojo do processo de acumulação capitalista (PRADO, Jr,2012), se dão as reformas estaduais do ensino primário e normal, sendo o professor a figura de maior destaque, o que faz com que os cursos de formação de professores primários recebam especial atenção nas reformas educacionais da década. Para tanto, toma como amostra para a análise, as reformas estaduais dos Estados de São Paulo, Minas Gerais e Rio Grande do Sul.

Em São Paulo a reforma se deu através da Lei n. 1750 de 8 de dezembro de 1920 assinada pelo Presidente do Estado, Dr. Washington Luis Pereira de Sousa, regulamentada pelo Decreto n. 3356 de 31 de maio de 1921. Em Minas Gerais, pelo Decreto n. 8.162, de 20 de janeiro de 1928 que aprova o Regulamento de Ensino nas Escolas Normais e pelo Decreto n. 8.225, de 11 de fevereiro de 1928 que aprova os programas do ensino normal. A reforma gaúcha se deu através do Decreto 4.277 de 13 de março de 1929, assinado por Getúlio Vargas e Oswaldo Aranha, que "provê sobre o ensino normal e complementar do Estado", pelo qual, é estabelecido o Regulamento do Ensino Normal do Estado do Rio Grande do Sul.

Através de pesquisa qualitativa de caráter teórico-documental, portanto, tendo como fonte primária a legislação educacional e documentos da época, busca evidenciar as condições determinantes da modernização dos cursos de formação de professores para os anos iniciais da escolarização na realidade brasileira, indicando as políticas educacionais e sua sinalização para uma relação direta da educação com as exigências do mundo do trabalho. Os argumentos principais a estas questões estão elencados na própria legislação que, alicerçada na prática pedagógica se constituem nos fundamentos da formação.

É importante lembrar que São Paulo se destacava no contexto nacional, visto que, desde o século XIX, o crescimento industrial de São Paulo se mantinha como uma atividade subordinada ao capital cafeeiro" (MORAES,1994, p.30), mas, especialmente a partir de 1920, assiste os primórdios da crise cafeeira com a transferência de capital do setor agrícola para o setor industrial e, em consequência, a perda do predomínio do campo sobre a cidade. Esta é a realidade que atinge também Minas Gerais, cuja economia agrária era predominante, assim como atinge a posição gaúcha de tradicional fornecedor do mercado interno do país, por ser a economia do Estado subsidiária de base fundamentalmente agropecuária.

No entanto, a industrialização não havia conquistado seu espaço político junto ao poder central. Era necessário buscar este espaço numa sociedade que se mantinha agrária e distanciada do progresso científico. Para tanto, a ideologia positivista fornecia os elementos necessários à implantação da nova ordem, visto que o surgimento da ideologia positivista se deu pela defesa da sociedade burguesa, de ordem industrial, buscando conciliar o progresso da indústria e a ascensão do desenvolvimento capitalista com a ordem da sociedade.

Compreendida no conjunto das transformações que se operam nos setores econômico, social e político do país, ligados ao fortalecimento do projeto do capital com consequências para o reordenamento da sociedade, evidencia, neste processo o foco de reflexão que permite compreender, nas questões educacionais, o papel do professor primário a partir das tensões que se inserem na sua formação.

\section{Os anos 20: o contexto, a educação e as perspectivas de mudança}

$\mathrm{Na}$ perspectiva de progresso com os interesses voltados para a industrialização, na década de 1920, o Brasil passou por transformações que, embora tivessem sido alicerçadas na base agrário-exportadora, provocaram mudanças nos centros urbanos, especialmente nos centros mais consolidados, representando um processo de transição econômica e social que parte do modelo agrário-exportador para um novo padrão de acumulação (PRADO. JR, 2012).

Este contexto atinge em cheio o projeto educacional da nação, como se pode verificar, por exemplo, no Decreto $\mathrm{n}^{\mathrm{o}} 7566$ de 1909: 
Considerando: que o aumento constante da população das cidades exige que se facilite às classes proletárias os meios de vencer as dificuldades sempre crescentes da luta pela existência; que para isso se torna necessário, não só habilitar os filhos dos desfavorecidos da fortuna com o indispensável preparo técnico e intelectual, como fazêlos adquirir hábitos de trabalho profícuo, que os afastará da ociosidade, escola do vício e do crime; que é um dos primeiros deveres do Govêrno da República formar cidadãos úteis à Nação. (Decreto Lei ${ }^{\circ}$. 7.566 de 23 de Setembro de 1909).

Neste sentido, o processo de industrialização no Brasil a partir da agricultura cafeeira e da grande indústria desenvolveram-se:

Sob a égide do capital financeiro, num momento determinado da expansão mundial do capitalismo que dispunha em seus mercados não só de capitais monetários mas também de meios de produção e de homens proletarizados-todos eles imprescindíveis para a formação do mercado interior do capitalismo no Brasil. (DECCA,1981, p.151.).

Sob a influência dos modelos importados que se configuravam na modernização das grandes cidades, nos produtos industrializados que circulavam, na grandiosidade das indústrias estrangeiras que se colocavam no país, na ideia de desenvolvimento e de progresso que perpassava a mentalidade da sociedade na época, as modernas ideias de educação são buscadas nos países desenvolvidos (SEVCENKO,1992), indo muito além do cotidiano de homens e mulheres acostumados à vida pacata dos hábitos rurais.

Neste contexto, um movimento que chamou a atenção foi o tenentista, pois diante do desafio que estava posto de construção da Nação e do Brasil moderno, os 'tenentes' que estavam participando do processo e inseridos nessa conjuntura, também representavam o "novo". Carone (1974) sinaliza que:

É com o tenentismo que acentua a fissura entre o velho e novo, entre o Exército político tradicional e o recente Exército político. [...]. Agora, porém, os traços que caracterizam o recente movimento político se acentuam, progressivamente, numa afirmação contínua. Como a dos sargentos, as revoltas tenentistas são coletivas e totalizantes. (CARONE, 1974, p. 383).

O movimento nacionalista, forte presença na época, desencadeado e liderado pelas Ligas Nacionalistas foi incentivado por grupos compostos por segmentos da elite e de camadas médias. Teve por objetivo consolidar uma cultura brasileira e afirmação de uma consciência política conforme os ditames da república liberal, ideia que exerceu grande influência sobre as políticas públicas do período (ANTUNHA, 1976).

Liderado pelos republicanos, este movimento identificava o regime republicano com a modernidade. A nacionalidade seria para eles "o resultado da luta contra o passado, a construção de uma nova sociedade organizada politicamente pelos nacionais e na qual as classes empresariais brasileiras teriam lugar de destaque" (OLIVEIRA, 1990, p.187), colocando na educação a fórmula mágica para a solução dos problemas sociais e do desenvolvimento econômico.

Junto, se destacava o nacionalismo da Associação Brasileira de Educação - ABE criada em 1924 no Rio de Janeiro por um grupo de intelectuais liderados por Heitor Lyra. Era 
a instituição no nível da sociedade que se salientava nos anos vinte com a discussão sobre a questão educacional em defesa da escola primária integral, cujos assuntos se constituíram pauta das Conferências Nacionais de Educação.

Evento marcadamente nacionalista, as Conferências Nacionais de Educação se constituíram em palco de propostas conservadoras e renovadoras e, é na perspectiva conservadora que o grupo católico da $\mathrm{ABE}$ propõe desde a $1^{\mathrm{a}}$ Conferência, realizada em Curitiba, em 1927, o ensino religioso como uma das alternativas de "uniformização doutrinária da escola".

Convictos da importância da educação como fator de desenvolvimento aos moldes dos países industrializados, os integrantes da ABE não se restringiram apenas à alfabetização, mas a uma proposta pedagógica para a escola primária em sua totalidade e, através da educação, seus desdobramentos: instrução e trabalho, destacando-se a $\mathrm{ABE}$ como principal órgão aglutinador das diferentes ideias e posições voltadas para o nacionalismo e a crença de que a educação estava acima de qualquer outro problema nacional. O lema da instituição era, segundo o Boletim da ABE (julho de 1927):

O problema da educação nacional só estará a caminho de ser resolvido no dia em que possuirmos uma 'elite' esclarecida e consciente, capaz de compreender sua importância e de empreender sua solução. Preparar uma 'elite' é, pois, o primeiro passo a realizar (BOLETIM da ABE, ano II, n. 6, jul./1927. p. 1).

Contrária às campanhas de alfabetização, voltava-se para a educação das elites, especialmente as elites dirigentes, para o que buscava convencer o povo de que a culpa do atraso do país não estava no analfabetismo e sim nas elites mal preparadas que nos governam e nas legiões de analfabetos, sempre crescentes, que as sustentam (CARVALHO,1986).

Era preciso, ao invés de 'apressadamente ensinar a ler, escrever e contar aos iletrados'- coisas da má pedagogia - 'cuidar seriamente de educar-lhes os filhos fazendo-lhes frequentar uma escola moderna que instrui e moraliza, que alumia e civiliza' (Boletim da ABE, n.8 apud CARVALHO,1986, p.101).

A situação da educação brasileira à época revelava o processo de exclusão a que era submetida a ampla maioria da população. O recenseamento de 1920 indicava que $80 \%$ da população era analfabeta (NAGLE, 1974, p.112). Esta realidade evidenciava um aumento de analfabetos frente aos dados de 1900, como apontava o Anuário Estatístico do Brasil do Instituto Nacional de Estatística que indicava o percentual de analfabetos no país em todas as idades de $75 \%$ e, na população de 15 anos, era de mais de $65 \%$.

Vencer o analfabetismo era prioridade do país, tal como demonstra Mário Pinto Serva em 1927 na I Conferência Nacional de Educação (I CNE) realizada em Curitiba ${ }^{1}$, ao apresentar o quadro de analfabetos do país a partir do levantamento estatístico por Estado, em 1920.

Apresentando o Distrito Federal como o de menor número de analfabetos $(38,7 \%)$, os Estados do Norte e do Nordeste com a maior percentagem, variando ente 70 e $88 \%$ de analfabetos, (SERVA, I CNE, Tese $n^{\circ} 103,1927$, p.643), verifica-se, a partir dos estudos de Serva

\footnotetext{
${ }^{1}$ A I Conferência Nacional de Educação (I CNE) foi uma iniciativa da Associação Brasileira de Educação (ABE) com o auxílio da Inspetoria Geral da Instrução Pública do Paraná. Evento foi realizado em Curitiba em 1927 e contou com mais de 300 participantes. Foram defendidas mais de 112 teses, versando sobre variados assuntos relacionados à educação do país. I CNE- recuperado de http://www.dominiopublico.gov.br/download/texto/me001825.pdf
} 
que os Estados em pauta neste estudo não apresentavam muito melhor situação do que os demais: São Paulo com 70,2; Minas Gerais com 79,3 e Rio Grande do Sul com 61,2\% de analfabetos.

O movimento nacionalista enfatizava a luta contra o analfabetismo, buscando combater "o maior mal da nação brasileira", o analfabetismo, "a grande vergonha do século, o máximo ultraje de um povo que vive a querer ingressar na moderna civilização" (SERVA,1933, p.29,30). Alfabetizar neste movimento era a ordem, assumindo o alfabeto importância por si mesmo.

\section{As reformas estaduais e o processo de modernização dos cursos de formação de professores primários}

$\mathrm{Na}$ disputa entre o pretendido e o existente, correspondendo aos ideais dos movimentos em defesa, tanto da sociedade urbano-industrial como da "civilização agrária", de 1920 a 1929 a instrução pública nos Estados e no Distrito Federal sofre alterações, não só no aspecto quantitativo das instituições escolares, como em relação às novas formas de organização e orientação das práticas pedagógicas que, efetivadas de "modo difuso e dentro das possibilidades postas pela realidade brasileira" (MORAES, 1992, p.29), promovem, especialmente na escola normal, suas mais significativas mudanças.

Para isso, governantes e reformadores, em conformidade com a modernidade assumida pelos países desenvolvidos garantem, pela legislação, uma escola pública, gratuita, obrigatória, um direito para homens e mulheres e, em alguns casos, laica.

Neste particular, na linha da Liga Nacionalista de São Paulo criada em 1917 se dá a Reforma Sampaio Dória em São Paulo, em 1920, uma das mais contraditórias da década, pela qual organiza uma escola primária, obrigatória, com duração de dois anos, voltada exclusivamente para a alfabetização, compreendida como a fórmula mágica para a reorientação dos costumes políticos.

Através do alfabeto buscava integrar o país ao mundo moderno com vistas à mudança do eixo de desenvolvimento pela recomposição do poder político, aos moldes da democracia liberal, o que levava à necessidade de aumentar o corpo de eleitores para o que se fazia necessária a alfabetização, visto que a Constituição Republicana de 1891, artigo 70, parágrafo $2^{\circ}$ impedia o voto do analfabeto.

Sampaio Dória enfatizava a obrigatoriedade do ensino primário. Destacava-se neste programa a preocupação com a formação cívico-nacionalista, seja através da educação moral e cívica, seja por medidas relacionadas à integração do estrangeiro ou pela proibição de línguas estrangeiras a menores de dez anos (art. $5^{\circ}$ da Lei 1750/20).

Mostrando uma certa rejeição aos métodos tradicionais, a Reforma Sampaio Dória modernizava a escola primária como decorrência de uma nova concepção de infância baseada nas descobertas da Psicologia. Para tanto, era preciso formar professores.

É neste momento que, através da crescente influência norte-americana, se afirmava no Brasil, no campo da educação, o escolanovismo ${ }^{2}$ representativo da ideologia liberal, compreendido como o ideário de educação "moderna", o que vai ao encontro das necessidades de justificação de implantação de uma nova ordem social e econômica, cuja inspiração teve sua expressão no capitalismo nascente.

Tendo como ponto comum a orientação pedagógica voltada para os ideais do movimento escolanovista, é o momento em que se introduzem nos currículos da escola normal, de forma sistemática, as ciências da educação com a valorização dos aspectos

\footnotetext{
${ }^{2} \mathrm{O}$ escolanvismo é um movimento que tem como "ponto de partida a Escola Tradicional já implantada segundo as diretrizes consubstanciadas" (SAVIANI,2008, p. 6). Começa criticando a pedagogia tradicional "esboçando uma nova maneira de interpretar a educação e ensaiando implantá-la". (Colocando a criança no centro do processo educativo), o que acontece na realidade é que a Escola Nova "aprimorou a qualidade de ensino destinado às elites".
} 
psicológicos, sociológicos e biológicos da educação como uma necessidade para socializar e adaptar o indivíduo à sociedade que se delineava.

Propugnava-se uma melhor especificidade ao nível da formação, a articulação com o ensino médio, a preocupação com as práticas pedagógicas nas quais assumem especial destaque as "escolas-modelo" e as "escolas de aplicação", instituições anexas às escolas normais, campo de prática aos futuros professores ou, dito de outra forma, campo de aprendizagem do "fazer pedagógico". Modernizava-se, assim, o curso de magistério primário, o que se traduziu, na escola, na relevância da questão metodológica.

Em São Paulo, apesar de não apresentar inovações significativas em relação às reformas anteriores, a Escola Normal proposta por Sampaio Dória, se constituiu num curso de quatro anos de duração (Art.246) e apresentou, em seu currículo, conforme artigo 247 do Decreto 3356 de maio de 1921, as "cadeiras" de Português, Latim, Literatura, Francês, Matemática, Física e Química, Anatomia e Fisiologia Humana; Biologia Vegetal e Animal; Higiene, Cosmografia, Geografia geral e Corografia do Brasil, História do Brasil e Geral, Psicologia e Pedagogia, Metodologia didática (Prática Pedagógica). Acresce-se a este elenco o "Orfeão Escolar" que deveria ser desenvolvido nas escolas normais, aos sábados (artigo 254). Ficavam ainda instituídas, as cadeiras de: Desenho; Música, e Ginástica (artigo 248).

Mesmo sendo de quatro anos a duração do curso, a Lei mencionava limitações para o desenvolvimento das disciplinas. Neste caso, a própria lei instituiu o desenvolvimento, de forma conjunta, em situações especiais, de todo o elenco de disciplinas. Com este propósito a lei definiu que, caso não existissem catedráticos ou, enquanto não comportarem secção masculina, as disciplinas deverão ser agrupadas devendo constituir-se em uma só cadeira.

Desta forma, conforme parágrafo único do artigo 247 do Decreto 3356/21, as disciplinas desta base curricular deverão ser desenvolvidas, "a primeira com a terceira, a quinta com a sexta, a sétima com a oitava, ficando criada uma cadeira conjunta de Latim e Literatura nas escolas em que não se lecionavam tais matérias.", o que evidencia uma racionalização de tempo, de espaço e de recursos humanos.

Comparativamente ao Curso Normal existente, a Reforma Sampaio Dória enriqueceu o currículo com o acréscimo das disciplinas relacionadas às ciências da educação, caso da Psicologia, além da Prática Pedagógica, da Pedagogia e da Didática, até então inexistentes.

Arroladas como ciências da educação se encontram a Biologia Educacional, a História da Educação, a Pedagogia Experimental, a Sociologia Educacional assumindo, no entanto, a Psicologia, o principal domínio científico, fornecendo elementos para transformar a escolarização numa técnica altamente racionalizada. Com a Psicologia, a tarefa educativa se libertava de ser compreendida como "questão de tato, de dom, de intuição, de prática, de vocação" (NAGLE,1976, p.247).

Não eram, no entanto, as questões científicas as preocupações da reforma Dória. Isto se justifica se compreendermos que, desde o começo do século, ganhava importância a questão cívica e moral na formação humana. É nesse quadro que se justificam os esforços e a produções das correntes nacionalistas, bem como as energias para proceder as campanhas de desanalfabetização do país.

Isto poderia justificar a reforma de 1920 , colocada entre o que se configurou como moderno nos padrões escolanovistas, e o que se colocou como suficiente numa sociedade sem exigências maiores em educação, que não o respeito à ordem instituída.

Sem ênfase nas ciências da educação, a escola normal se assegurava nos conhecimentos gerais e, para isto, é criada a escola complementar de 3 anos. Anexas às escolas normais (art.196 do Decreto 3356/21), "o fim da escola complementar é o de preparar alunos que já tiverem feito o curso médio para, sem solução de continuidade, prosseguir os seus estudos nas escolas normais ou nos ginásios" (art.197). Eram escolas, cujo propósito era ampliar a base de formação geral na formação do professor. 
O artigo $8^{\circ}$ da Lei 1750/20, item $\mathrm{h}$, cria classes mistas nas escolas normais em que a frequência às classes masculinas for insuficiente: "A escola normal da Praça da República terá, permanentemente, duas classes femininas e uma masculina em cada ano, esta pela manhã e aquelas à tarde" (art.245)

Registra-se, nesta reforma, a proposta de criação de uma Faculdade de Educação que, apesar de não ser uma ideia nova, seria um recurso de aperfeiçoamento para o magistério no "instituto de aperfeiçoamento pedagógico e cultura geral", criado sob o nome de Faculdade de Educação (art.21 da Lei 1750/20). No Capítulo III intitulado "Do espírito e orientação do ensino nas escolas normais" observa-se a tendência à um ensino prático, voltado para métodos ativos, quando diz que

[...] o ensino nas escolas normais deve ser feito, tanto quanto possível, pelo aprendizado ativo e individual do educando, e além do fim de aplicação utilitária de cada cadeira ou aula, deve procurar desenvolver o espírito do aluno, dando-lhe iniciativa intelectual e faculdade crítica (SP, Decreto 3356/21, Art.255).

Neste processo, apesar da frágil base científica em que se apoiava a formação do professor, havia uma tendência à modernização de seus métodos, fugindo do ensino verbalístico e enciclopédico predominante na escola tradicional.

Esta era uma tendência desde 1890, evidenciada na primeira reforma do ensino primário e normal do período republicano, a Reforma Caetano de Campos, quando entrou a escola de formação de professores em uma nova fase, sofrendo influência de ideias americanas através de seus professores com formação ou experiências em escolas americanas. Nesta fase se criaram as "escolas-modelo" "que serviam de campo de aprendizagem prática do professor e de experimentação de novos métodos."

Caetano de Campos justificava a "escola-modelo" como a grande revolução na formação de professores e citando Pestalozzi, por ser a base das metodologias "em países mais avançados", afirmava que é pela "educação renovada que a civilização brasileira será promovida. Para isso, é necessário formar mestres e é para isso que se reforma o Curso Normal. Outros povos já avançaram seu desenvolvimento", dizia. "São os modelos. É preciso imitá-los, não com cópias e, sim, com adaptações. É pela adaptação, portanto, e não pela adoção de modelos que se aperfeiçoa a educação e, é nas "Escolas-Modelo", funcionando como laboratórios, que serão testados os novos métodos" (apud REIS FILHO,1981, p.68). Cunha, ao analisar esta situação do início da República, afirma:

A situação era propícia à penetração de ideias novas, que chegavam em grande quantidade da Europa ou dos Estados Unidos. Os nossos intelectuais as recebiam, divulgavam-nas, defendiam-nas sem, contudo, submetê-las a um processo crítico. Nem havia condições para isso. Os centros de ensino superior que então possuíamos, pela feição profissionalizante que os caracterizava, como ao tempo de D. João VI, não tinham massa crítica para este mister. No entanto, o entusiasmo do intelectual brasileiro com as novidades d'além mar exerceriam um papel positivo, na medida em que tais ideias iam pondo para fora nosso subdesenvolvimento cultural, econômico, político e social (CUNHA,1989, p.51).

Voltada para métodos, em conformidade com o desenvolvimento da infância, sem ênfase nas teorias que lhe dão suporte, justificava-se, portanto, a "Escola-Modelo" como um 
centro de treinamento, dissociado de seus enfoques teóricos. Isto implicava em uma formação deficiente na base, tendo como marca característica a dissociação entre a teoria e a prática. $\mathrm{O}$ trabalho manual, a música, o canto e a educação moral religiosa eram importantes elementos do método. A educação religiosa encontrava-se em relação inseparável com a educação moral devendo ser realizada como vivência imediata e prática.

Exigência da educação pública nos Estados modernos, a Lei Sampaio Dória privilegiava no Título II, a gratuidade do ensino, no Título III, a laicidade e no Título IV, a obrigatoriedade escolar e, neste caso, esta lei se colocava em conformidade com as exigências modernas. O padrão era a realidade americana do Norte, servindo de modelo para a Constituição, para a ordem industrial que se implantava e para a escola necessária à esta ordem. Dória apenas seguia o caminho das reformas republicanas.

Neste cenário, havia a necessidade de maior organização da escola normal que tinha como compromisso formar professores em conformidade com a ordem social emergente acrescentando, ao rol de conhecimentos gerais, disciplinas profissionalizantes de base científica e, assim, parecia que a escola se modernizava em seus conhecimentos e seus métodos.

Para tanto, o professor tradicional, voltado para uma formação intelectual, não servia mais para a escola primária. Não era necessária uma formação intelectual ao profissional que tinha compromisso com a classe que naturalmente estava destinada ao trabalho manual. Assim, através do trabalho do professor se organizava uma nova mentalidade voltada para a divisão do trabalho, para o aprender a fazer e não para o aprender a pensar.

Neste processo, a luta dos movimentos nacionalistas, que buscavam pela educação a mudança da sociedade, não se constituiu na luta dos proprietários rurais. Para estes, não havia importância o processo educacional. Não seriam, portanto, eles, a questionar uma escola primária de dois anos e, tampouco, questionar a falta de vagas para resolver o problema do analfabetismo. A exclusão pela escola não alteraria a ordem rural existente.

Para a classe rural, era mais importante a ordem moral instituída pela escola do que a formação intelectual. Pode-se dizer com Cunha (1986, p.218) que, neste contexto, não era o analfabetismo o maior mal do país e, "sim, a falta de uma direção moral que orientasse a conduta, os sentimentos e o caráter dos trabalhadores".

Este é o caso do artigo 256 do Decreto 3356/21 que determinava que a educação cívica, na escola normal, seria ministrada aos alunos de forma prática, "fazendo-se, tanto quanto possível, por meio de exercícios representativos, sobre o ensino de nossas instituições". Para isso, conforme parágrafo único do mesmo artigo, deveria haver em cada escola normal, uma associação de estudantes.

$\mathrm{Na}$ escola complementar, a formação cívica se integrava aos programas de tal forma que, conferida pelo artigo 13 da Lei 1750/20, o governo ficava autorizado a reorganizar o período de aulas e os programas instituindo a "máxima autonomia didática", "como o escotismo e as linhas de tiro", compatível com a "unidade e eficiência do ensino".

Falava mais alto o positivismo visto que "as leis que a ciência positiva descobrira, e que a distinguiam do empirismo, eram positivas também no sentido de afirmarem a ordem estabelecida como base para a negação da necessidade de construção de uma nova ordem" (MARCUSE,1978, p.315).

Assim, era garantida a manutenção da ordem existente, onde a predominância do setor agrário-exportador não era posta em dúvida, nem mesmo pelos mais lúcidos representantes da indústria.

Nesta perspectiva, a Reforma Dória se colocava como uma reforma essencialmente conservadora, pois "combinava exemplarmente elementos do positivismo e do liberalismo com disciplina de trabalho", uma nova visão de educação, assentada na "parcimônia dos gastos" na perspectiva de uma sociedade urbano-industrial, ajustando este modelo, "ao setor mais dinâmico das classes dominantes, a burguesia cafeeira" (HARDMAN,1988, p.93). 
Assim, por um lado voltado para o "aprender a fazer" e, por outro, uma rejeição aos métodos tradicionais, se organizava a política educacional da época, pela qual se formavam professores para uma escola primária que se modernizava como decorrência de uma nova concepção de infância baseada nas descobertas da Psicologia. Isto instituiu, como centro da escola primária, o "método natural" que é:

A intuição, a lição de coisas, o contato da inteligência com as realidades que se ensinam, mediante a observação e a experimentação, feitas com alunos e orientadas pelo professor. São expressamente banidas da escola, as tarefas de mera decoração, os processos que apelem exclusivamente para a memória verbal, a substituição das coisas e fatos pelos livros que se devem apenas usar como auxiliares do ensino (SP, Decreto n. 3.356/1921, Art. 103).

A metodologia, portanto, era o centro das inovações nesta reforma, visto que "lições de coisas" identificava este caráter no generalizado método intuitivo, determinando uma mudança de postura pedagógica. Neste quadro, assumia "lugar de excelência", na formação do professor, a "escola modelo", constituindo-se em uma identidade do "moderno" no curso normal, visto que, desde 1890, com a reforma Caetano de Campos e, tal qual o pensamento deste reformador, a "escola-modelo" era a grande revolução na formação de professores.

A reforma Dória efetivada em 1920 abriu caminhos para reformas que se dão na década nos demais Estados brasileiros, distantes, no entanto, da escola primária paulista. Salientam-se, aqui, exemplarmente, as reformas da escola normal mineira em 1928 e da escola normal gaúcha em 1929.

Em Minas Gerais, a remodelação da escola foi intento central da Reforma Francisco Campos, a qual retomou a questão do analfabetismo através de uma escola primária integral. Para tanto, a necessidade de formar professores, o que, pelo Decreto 8.162 de 20 de janeiro de 1928, sofrendo influências da ABE e de suas posições sobre a educação para uma civilização em mudança e a crença na educação como fator de reconstrução social, volta a atenção para a questão da qualidade e da democratização da escola primária e, naturalmente, para a formação de seus professores.

Voltada para formar "cidadãos", a reforma mineira buscava formar professores no "espírito da reforma", o que levava ao Curso Normal significativas mudanças em relação à Escola Normal existente, tendo em vista que, nesta reforma, era este curso que daria suporte ao profissional responsável pelo êxito ou pelo fracasso da escola primária, a base para a formação de uma nova ordem.

Considerando as incumbências profissionais do professor, o Regulamento do Ensino Normal da reforma mineira estabelecido pelo Decreto n. 8162/28, ressaltava que o Curso Normal "tem por objeto formar professores e demais pessoal técnico para o ensino primário do Estado, e será ministrado em duas categorias de escolas: - do primeiro e do segundo grau” (art.1 ${ }^{\circ}$ ). Conforme parágrafo único, do mesmo artigo, "haverá, além disso, nos cursos de primeira e de segunda categoria, um curso de dois anos destinado à formação de professores rurais".

O curso normal estava organizado em sete anos divididos em Curso de Adaptação, Curso Preparatório com a finalidade de ser a base de conhecimentos gerais e Curso de Aplicação, com duração de dois anos, sendo este último, o curso normal propriamente dito. Junto ao Curso de Aplicação era previsto o Curso de Aperfeiçoamento voltado para métodos e técnicas como proposta de educação continuada.

Da importância que assume o professor nas mudanças políticas propostas, decorre a criação de 21 Escolas Normais no Estado, neste período, contra apenas duas escolas normais 
oficiais existentes. Destacada a sua importância, a escola normal recebeu na reforma mineira uma estrutura diferenciada e complexa estabelecida pelo "Regulamento do Ensino Normal".

O ensino primário vale o que valerem seus professores e o valor destes estará, necessariamente em função do Curso Normal. Será, conseguintemente, tarefa destituída de seriedade nos seus objetivos, rever o curriculum primário refundindo-lhe os programas, estatuindo sobre métodos e processos de ensino, renovando-lhe o espírito e demarcando-lhe novas e largas finalidades se, ao mesmo tempo, não se procurar formar a mentalidade do professor primário à medida das exigências a que ele tem de satisfazer, ordenando-lhe, desde cedo, o espírito no quadro intelectual e profissional, em que é chamado a exercer sua atividade. (MG. Exposição de Motivos do Decreto $\mathrm{n}^{\circ}$. 8.162 - aprova o Regulamento das Escolas Normais Mineiras).

Na defesa de seus propósitos, Campos buscou em Dewey, Claparede e Decroly a base teórica, tanto para a sua proposta de formação de professores, como para a escola primária sendo, nesta, o aluno, o centro do processo pedagógico, onde o respeito à criança a partir de suas características psico-biológicas, faziam do ato de ensino um processo natural. Neste processo, a criança não deve ser considerada do ponto de vista do adulto, mas do ponto de vista dos motivos e interesses próprios dela, o que alterava profundamente a base teórica e os procedimentos didáticos da formação do professor.

Tendo por base os princípios da Escola Nova, a Exposição de Motivos do Decreto 8162/28, salientava a importância do curso normal pelas exigências do mundo contemporâneo, pelos imperativos da ciência, da indústria, do trabalho e da cultura, o que exigia uma mudança de postura da velha escola normal.

Se quisermos encontrar a origem de todo esse momento, que se assemelha a um ato de despejo das velhas escolas adormecidas na sua prática e na sua rotina, deveremos nos dirigir, não aos práticos do ensino, mas ao Instituto Jean-Jacques em Genebra, à Universidade de Bruxelas, às Universidades americanas, às Universidades da Áustria e da Alemanha, aos psicólogos, aos Stern, aos Spranger, aos Claparede, aos Decroly, aos Dewey" (MG. Exposição de Motivos do Decreto 8162 de 20 de janeiro de 1928).

Nesta perspectiva, para desenvolver "Lições de Coisas" na escola primária o professor recebia noções de metodologia que, conforme o programa do curso normal tratava da:

[...] importância das lições de coisas, seu caráter educativo; unidade do objeto mental; os centros de interesse e a organização das noções de coisas. A graduação das lições de coisas e a evolução dos interesses infantis (MG. Programas do Curso Normal. Decreto n. 8225 de 12 de fevereiro de 1928).

Considerando que 79\% da população do Estado de Minas Gerais em 1920 era rural (BASBAUM,1976, p.141), justificava-se a emergência de formação de professores para esta área, para o que se organizavam cursos rurais de formação de professores na reforma mineira que, pelo Decreto 8162/28, artigo 25, “deverão fornecer professores para a regência de escolas rurais” em cursos gratuitos de 2 anos de duração (Art. 26). 
De modo a atender a sociedade nas suas diferenças, pobre em sua estrutura e sem exigências científicas, o curso normal rural se identificava com as características do meio a que se destinava. Pode-se dizer que o mesmo refletia o meio a que pertencia sendo um curso prático, por excelência, voltado para as necessidades do trabalho no meio rural.

Disto se depreende que, nesta modalidade, formar professores primários para o ensino rural, correspondeu a uma medida imediatista que, voltada para o "aprender a fazer", se moldava à estrutura rural atrasada. $\mathrm{O}$ artigo 33 e seguintes explicitam:

[...] terão as professoras do curso rural o dever de executar com eficiência os programas e horários do referido curso, compenetrandose das responsabilidades que lhes cabem, na formação de professores destinados a resolver o importante problema do ensino às crianças da zona rural (MG. Decreto 8162/1928, art.33).

No cumprimento desta tarefa, o professor deverá se valer de "métodos intuitivos" (art.34) devendo a prática pedagógica se constituir, no $1^{\circ}$ ano, "num curso de participação" e, no segundo ano, em aulas que os alunos da classe darão para os colegas "com a assistência e orientação da professora do curso, que os auxiliará a preparar as lições, notando suas falhas e lacunas, retificando as primeiras e preenchendo as segundas" (art. 35).

Frágil base teórica, duração do curso insuficiente, ausência de disciplinas científicas além das precárias condições para desenvolver um trabalho voltado para o mundo moderno e seu dinamismo, característica dos cursos rurais, os mesmos sinalizavam a despreocupação do legislador em, efetivamente, modificar a situação real, considerando o alto grau de analfabetos do campo e a perspectiva de modernização da mais importante fonte de recursos do Estado.

Se oferecia a educação sem, no entanto, desestruturar a ordem estabelecida. Assegurava-se, assim, a formação de uma classe trabalhadora rural aos moldes do latifúndio existente, onde nenhum projeto de modernidade se incluía, assumindo aí, o professor, a principal incumbência nesta tarefa.

A segunda modalidade de formação de professores compreendia o ensino nas escolas de primeiro grau, onde se ministraria o curso normal de primeiro grau sendo estas, escolas particulares, reconhecidas e fiscalizadas pelo Estado (art.21). Recebendo candidatos aprovados no $2^{\circ}$ ano do curso de adaptação (art.24), o curso normal de primeiro grau terá, conforme determinação do artigo 23, a duração de três anos.

O Curso Normal, propriamente dito, Curso de $2^{\circ}$ grau, de competência do Estado constará de três cursos: o de adaptação com dois anos de duração, o preparatório com três anos e o de aplicação com dois anos (art. $3^{\circ}$.), o que totalizava sete anos reservados à preparação do magistério primário. A presença da Psicologia e da Biologia no programa era justificada por serem disciplinas indispensáveis ao desenvolvimento das metodologias, ponto fundamental de toda a proposta.

[...] se os métodos e técnicas de ensino começam a prestar contas à biologia e à psicologia, sem erro de ofício...(...)Eis como a psicologia, não apenas a psicologia geral, mas a psicologia educacional, constituem parte indispensável ao equipamento intelectual do professor primário.(...) Em um plano de reforma de ensino normal, não poderia deixar de ser conferido à Psicologia Educacional o lugar que lhe compete, não somente no plano da cultura geral, mas e, principalmente, no plano destinado à aquisição de técnicas pedagógicas (MG. Exposição de Motivos do Decreto 8162 de 20 de janeiro de 1928). 
Por sua vez, "história dos métodos", integrante do programa, era justificada na Exposição de Motivos como uma necessidade para a melhor aplicação dos mesmos, pois "o melhor meio de conhecer a 'cousa' é conhecer a sua gênese, tal o postulado do método genético, de corrente aplicação em todos os domínios científicos”. Assim:

O conhecimento dos métodos e processos de ensino, assim como de seus resultados, só poderá ser adquirido mediante a sua história e suas tentativas, dos seus sucessos, das suas aplicações (MG. Exposição de Motivos do Decreto 8162/1928).

A preocupação com as metodologias era uma constante no Regulamento do Ensino Normal, ficando clara a ideia de participação do aluno no processo ensino-aprendizagem.

As lições não constituirão monólogos do professor ou conferências sobre a matéria com o fito de tudo dizer e de tudo elucidar; o professor deve apelar para a colaboração dos alunos, suscitando-lhes o gosto da investigação da reflexão, de maneira a lhes despertar e exercer as aptidões à atividade e à iniciativa intelectual (MG. Decreto 8126/28, art.41).

Disto decorre que:

[...] ] professor terá o cuidado de não se limitar ao método expositivo; terá sempre presente ao espírito que a colaboração e atividade dos alunos é essencial à sua formação profissional, devendo exigir dos mesmos iniciativas, trabalhos de documentação e de investigação, de maneira a despertar-lhes o sentido da responsabilidade e do esforço pessoal (MG.Decreto 8162/28, art.44).

Além destas determinações, o Decreto continuava sua preocupação com a metodologia associando a esta os conteúdos de maior importância dos programas, quando, no Capítulo II estabelecia a importância de palestras, conferências e excursões como imprescindíveis para o enriquecimento do ensino. Neste caso, assumia maior importância, o professor da disciplina de Metodologia.

Os professores das escolas, particularmente os de metodologia, organizarão programas de conferências relativas a temas que versem, de preferência, sobre exercícios complementares ou estudo e desenvolvimento de pontos mais importantes dos programas, preferidos sempre, aqueles sobre os quais hajam aos alunos realizado investigações e documentação ou planejado projetos de estudo e solução (MG. Decreto 8162/28, art.52).

Nesta tarefa, se comprometeria, também, diretamente, o diretor da escola.

No começo de cada trimestre, o diretor da escola organizará, com o concurso dos demais professores, inscrevendo-as em um registro, listas sobre: a) obras relativas aos exercícios complementares, destinadas à leitura em cada classe; b) palestras dos alunos; c) conferências dos professores; d) excursões a serem realizadas, no curso do trimestre, pelos alunos do curso de aplicação das Escolas de 
$2^{\circ}$ Grau ou do último ano normal nas Escolas de Primeiro Grau (MG. Decreto 8162/28, art.55).

Ressalta-se, aqui, a ampliação da parte profissionalizante, no seu aspecto pedagógico e, nesta, o papel desempenhado pelas escolas de aplicação e dos cursos de férias. Enquanto os cursos de férias tinham como objetivo o aperfeiçoamento contínuo dos professores em serviço, as escolas de aplicação, funcionando como instituições anexas à Escola Normal, serviam de campo de prática aos futuros professores, assim como, se constituíam em núcleos de renovação do Curso Normal.

Desta forma, as escolas de aplicação serviam à prática profissional que, conforme o artigo 63 se dividia em aulas modelos, aulas didáticas, preparo de lições e lições práticas.

Neste particular, atenta-se para os programas de Psicologia da Criança que, desenvolvendo estudos de Pedologia, Pedotecnia, Pedagogia, tinham nos testes, a sua representação gráfica.

Os 'tests' em geral: 'tests' colletivos e 'tests' individuaes; 'tests' de aptidão e 'tests' de desenvolvimento. Os 'tests' de associação de idéas. O 'tests' da attenção. Os 'tests' da memoria. Os 'tests' da imaginação. Os 'tests' da evolução e da aptidão da creança por meio do desenho e da escripta. Os 'tests' da intelligencia. Os 'tests' do caracter... (MG. Decreto n. 8225 de 12 de fevereiro de 1928 que approva os programmas do ensino normal).

Estabelecia-se, neste momento, o fenômeno que Saviani denomina de "biopsicologização da sociedade, da educação e da escola." As anormalidades psíquicas e biológicas eram detectadas através de testes de inteligência, de personalidade, especialmente. "Forja-se, então, uma pedagogia que advoga um tratamento diferencial a partir da 'descoberta' das diferenças individuais" (SAVIANI,1984, p.12).

Nesta perspectiva, introduziam-se, através da escola, a partir da reforma mineira, os princípios diferenciadores de indivíduos, muito ao gosto de uma sociedade de classes, pelos quais se diferençavam alunos, não só através de testes, como pelo tipo de escola que frequentavam. A isto, acrescem-se os elementos diferenciadores de professores, estabelecidos através do tipo de formação recebida.

As diferenças entre os professores eram diretamente proporcionais às diferenças de suas clientelas. Aos alunos rurais, destinados à lidas rudimentares, professores rurais de pouca formação técnico-científica, além da precária formação geral; aos alunos urbanos, professores do curso normal propriamente dito para tratar com as camadas mais favorecidas.

Assim, se identificava na formação do professor uma formação voltada para a divisão do trabalho, pois, favorecendo as ciências para uns, caso dos cursos de aperfeiçoamento, e marginalizando outros que a elas não têm acesso, caso dos professores rurais e dos professores de $1^{\circ}$ grau, a reforma mineira, apesar de não colocar barreiras para o professor ampliar a sua qualificação, não deixava de evidenciar a distinção que estabelece nos diferentes níveis de formação, instituindo na mesma classe profissional, uma diferenciação social, via preparo profissional.

Formava-se, no próprio magistério, uma categoria de elite, o que se justificava pela postura autoritária de Campos, elite esta, no entanto, limitada à execução do processo pedagógico, visto que a estes professores, não era possibilitada a condição de pensar o processo pedagógico.

Refletindo influências da racionalização do trabalho, poderoso instrumento de diferenciação social, é possível dizer, a partir destas considerações, que a escola normal mineira estava sendo organizada para legitimar uma sociedade de classes aos moldes da estrutura capitalista. 
Na defesa desta posição, a necessidade de produzir "civismo", "civismo das elites" devotados às causas nacionais. "Civismo do povo dedicado a produzir riquezas - civismo que espera conduzir o país aos caminhos do que se entendia como progresso" (CARVALHO,1986, p.94).

Havia um discurso de modernidade através dos métodos, dos programas, dos recursos didáticos numa sociedade que se afirmava no processo de acumulação capitalista, frente ao mundo que se desenvolvia sob a égide da indústria, da troca, do mercado, do lucro.

Nesta perspectiva, o professor, responsável pela condução do processo, recebia especial atenção, pois a ele era confiado o papel de, sem alterar a sociedade existente, introduzir novas formas de comportamento, uma preparação passiva para a aceitação de uma sociedade em mudanças, o que indica que, mesmo sob outra estratégia, outro discurso, se valendo de novos processos, a reforma mineira não se afastava dos propósitos da reforma paulista, onde, ao magistério é imputado o compromisso de, por um lado introduzir uma nova visão de trabalho e de sociedade e, por outro, garantir uma conformação nacional à sociedade existente.

No Rio Grande do Sul, a reforma gaúcha, por sua vez, se dá através Decreto n. 4277 de 13 de março de 1929, o qual "provê sobre o ensino normal e complementar do Estado". Com este Decreto, as tendências de renovação da educação que começam a se delinear na realidade brasileira, principalmente por iniciativa da $\mathrm{ABE}$ neste período, iniciam sua caminhada no Estado, bem como, com esta reforma, o Rio Grande se alinhava no movimento escolanovista que se propagava no Brasil

Getúlio Vargas, então Presidente do Estado do Rio Grande do Sul, e Osvaldo Aranha, Secretário dos Negócios do Interior, promovem a reorganização do Curso de formação de professores primários, salientando-se esta reforma como a mais importante medida de educação do período por apresentar modalidades diversificadas de formação e de atualização do professor.

Ao mencionar o "Regulamento da Instrução Pública", o Decreto de 1929 refere-se ao Decreto n. 3.898 de 4 de outubro de 1927, referendando-o, ficando evidente que o governo Vargas, neste período, não realiza uma reforma do ensino primário, mas busca uma renovação da educação por meio do professor, o que justifica, neste governo, apenas a reforma do Curso Normal.

Assinado por Protásio Alves, o Decreto n. 3.898 de 1927 determinava em seu artigo $6^{\circ}$ que "haverá escolas complementares com o objetivo de desenvolver o ensino primário e preparar candidatos ao magistério público", o que indica que até 1929, a formação de professores primários era efetivada em estabelecimentos de ensino denominados de "Escola Complementar" denominação esta, adotada a partir de 1906.

A Secção VI do Decreto de 1927 tratava "Da organização e regimen das escolas complementares", instituindo no Art. $34^{\circ}$ tempo de duração e disciplinas do curso, bem como o Art. $36^{\circ}$ determinava que "Annexo a cada escola complementar haverá um collegio elementar para a pratica dos alunos de methodologia".

Por sua vez, o Decreto de 1929, determinava que "o ensino Normal é leigo, livre e gratuito, ministrado pelo Estado na Escola Normal de Porto Alegre e em Escolas Complementares localizadas nas cidades onde o Governo julgar conveniente" (art. $1^{\circ}$ ). Deste modo, o Governo do Estado define, particularmente, a Escola Normal de Porto Alegre que deverá ser um estabelecimento destinado à formação propedêutica e profissional de candidatos de ambos os sexos ao exercício do magistério público em todos os seus graus, $\left(\operatorname{art} .7^{\circ}\right)$. Oswaldo Aranha, ao apresentar o Relatório de sua Pasta em 1929, declara:

A situação do ensino não se resolve pela quantidade, mas pela qualidade. Cumpre ao Estado libertar a nossa infância dos males de uma alfabetização precária, inócua, procurando fazer da escola um elemento dinâmico e reformador, capaz de contribuir para a obra de transformação social, reagindo sobre a família e sobre o meio em geral 
e levando até às suas camadas mais profundas as suas influências e os seus benefícios (apud BUSATO,1983, p.135).

Condenando as campanhas de alfabetização e defendendo um projeto mais amplo de educação, continua Oswaldo Aranha:

Alfabetizar não é educar: é apenas ensinar. O Estado precisa ensinar e educar. A escola não deve ser unicamente uma casa de ensino, mas de educação. A criança precisa aprender a ler, a viver e a trabalhar na escola....A escola moderna transformou a escola antiga, a velha escola primária de letras, em uma verdadeira oficina de aprendizagem social. A escola hoje deve ser uma casa de atividade, de experiência, de trabalho e não a mansão do alfabeto (apud BUZATO, 1983, p.135)

A presença da educação cívica é ressaltada no documento de 1929 , no parágrafo $2^{\circ}$ do artigo $1^{\circ}$, ao determinar que "o professor se valerá de todos os ensejos, principalmente durante o recreio, para ministrar aos alunos, conhecimentos de civilidade", enquanto o parágrafo $3^{\circ}$ enfatizava os exercícios físicos, que deverão ser "praticados diária $e$ metodicamente, visando eles, o desenvolvimento corporal dos alunos. '

Neste quadro se salienta a disciplina denominada "Lições de Coisas" que, nesta proposta, não assume um caráter metodológico, tal qual assumiu na reforma Dória em São Paulo e sim um complemento de conhecimentos necessários à integração do aluno na sociedade que se modernizava, tendo nos conhecimentos científicos e técnicos, a sua base.

O Decreto de 1929 em seu Título II, artigo $8^{\circ}$, trata da Escola Normal de Porto Alegre, constituída dos seguintes cursos: a) Curso Complementar de três anos, que compreende as Escola Complementares comuns; b) Curso Normal ou de Aperfeiçoamento, dividido em 2 anos; c) Curso de Aplicação em 6 anos, sendo 4 de ensino primário e 2 de ensino elementar superior; d) Curso de ensino ativo, em 2 anos; e) Jardim de Infância.

Observa-se que não estão determinadas pelo Decreto de 1929 a abertura de Escolas Normais no interior do Estado. A formação de professores, aí, será efetivada pelas Escolas Complementares já existentes, organizadas em conformidade com o Decreto de 1927, acrescidos em 1929 de dois anos de aperfeiçoamento e modificações em seus currículos e em seus métodos.

Após cursar a escola Complementar, os futuros mestres poderão buscar aperfeiçoamento na capital do Estado, na Escola Normal ou Curso de Aperfeiçoamento.

As aulas de Pedagogia, Didática e Legislação do ensino do Curso Normal são nunca menos de dez por semana; as de Álgebra e Geometria, Literatura Vernácula, Psicologia Experimental Aplicada à Educação e de Higiene Geral, Higiene Escolar e Puericultura são em número de oito e as demais, nunca menos de quatro, conforme a importância da cadeira e de acordo com o Diretor da Escola (RS, Decreto 4277/1929, art. 36).

O Decreto de 1929 oferecia a oportunidade de aperfeiçoamento para professores, através de Cursos de Férias que deveriam ser realizados na Escola Normal de Porto Alegre, nos meses de janeiro e fevereiro, constando de "conferências e preleções, acompanhadas, quanto possível, de demonstrações práticas e projeções luminosas. ” (art.189 - Decreto 4277/1929).

A Escola de Aplicação ficava mais restrita a um espaço de observação das questões gerais de ensino, do que propriamente campo de prática pedagógica aos alunos normalistas, pois, como indica o artigo $41^{\circ}$ : 
[...] os alunos do terceiro ano do curso complementar e os do Curso normal acompanharão, no Curso de Aplicação, não só as aulas de Didática, como também os serviços administrativos e tudo quanto se relacione com a execução do regulamento e programa do Ensino primário...

Não tendo espaço para a prática na Escola de Aplicação, as experiências pedagógicas dos futuros professores, pelo Decreto de 1929, ficavam limitadas mais claramente ao Jardim de Infância, tendo em vista o que propunha o artigo $29^{\circ}$, ítem g: "fazer da escola infantil, menos um auditório, do que um laboratório de atividades, experiências e exercícios educativos", o que, de certa forma, reproduzia o artigo 36 da Lei de 1927.

Com isto, pode-se dizer que a reforma de 1929 não se afastava do que foi proposto em 1927, preparando o professor para formar alunos que pudessem assumir as funções sociais que a sociedade urbano-industrial requeria. O que mudava, agora, na proposta de 1929, é o aluno como centro do processo, os métodos, mas não os propósitos.

Fica evidente, portanto, o papel destinado à escola de preparar o aluno para a sociedade industrial, através da formação do professor, nas reformas da década de 1920, no Rio Grande do Sul, tanto por seus métodos voltados para a prática, quanto pelo tipo de formação de professores voltada, não só para atender às exigências da escola primária, como para trabalhar em creches e maternais, situação específica das sociedades industriais. Nisto, o Decreto de 1929, comprometia-se com a formação do professor para esta tarefa, já especificada no Decreto de 1927 na Secção II que trata da "Organização e regimen das escolas maternaes".

Conforme Decreto de 1927, a preocupação com a formação cívica, nos colégios elementares, é claramente definida no parágrafo $3^{\circ}$ do artigo $26^{\circ}$ quando determina que " não poderão ter categoria de docentes, os professores que não ministrarem o ensino de todas as matérias do programa, compreendidas as preleções semanais sobre assuntos da moral, civismo e higiene."

Isto se explica pela forte influência positivista, onde o aperfeiçoamento moral é objeto da educação e, nesta perspectiva, se destacava o positivismo gaúcho no país, o que se evidencia em 1927, quando da Primeira Conferência Brasileira de Educação, realizada pela ABE em Curitiba pois, conforme Carvalho (1986, p.234), foi "muito aplaudida a tese de Raul Bitencourt, delegado do Rio Grande do Sul sobre "Da Necessidade da Educação Moral no Ensino Secundário e Superior", sobre o tema da moral e do civismo, a tônica da conferência.

A moral, assim, é parte integrante do sistema de educação positivista. O homem, cumprindo o seu dever, estaria promovendo o progresso. A educação, nesta visão, deve organizar-se de modo a que os sujeitos sejam educados para a obediência às leis, por meio de cultos cívicos.

O que ficava evidente nas reformas dos Estados em pauta era a tentativa de modernizar o Estado, sendo o professor o elemento imprescindível para esta mudança que, sem alterar o predomínio da estrutura rural organizada, introduziria, via escola, novas formas de relacionamento, novas técnicas de trabalho, enfim, a ideia do moderno. Afinal, a ideia de moderno estava no ar e a educação entrava no plano do que Hardman (1988) chama de "metamorfoses ideológicas próprias do momento de origem e dispersão do sistema moderno da fábrica".

Havia um clima de entusiasmo contagiante entendido como expressão do progresso e, neste clima, a fábrica representava o avanço, a possibilidade do novo, enquanto a estrutura rural existente, representava a certeza.

Falava mais alto, portanto, o positivismo visto que "as leis que a ciência positiva descobrira e que a distinguiam do empirismo, eram positivas também no sentido de afirmarem a ordem estabelecida como base para a negação da necessidade de construção de uma nova ordem” (MARCUSE,1978, p.315). Positivismo e liberalismo eram os fundamentos 
ideológicos da formação de professores, tanto para manter a ordem existente, como para afirmar o processo de modernização da sociedade.

Pelo positivismo, força ideológica dominante no país, são traçados os destinos da educação brasileira pela separação entre teoria e prática, entre ciência e técnica, entre o saber e o fazer, considerando com Chauí (1980, p. 27-28), que "a influência positivista estabelece uma posição de subordinação da prática à teoria e não de relação entre as mesmas. A teoria é reduzida à organização e sistematização hierárquica das ideias". Nesta perspectiva, a formação não tem compromisso com a explicação ou compreensão dos fenômenos naturais e humanos a partir de suas raízes e, sim com a prática, colocada apenas como um mero instrumento técnico para aplicação das regras determinadas pela teoria.

Por sua vez, a influência liberal na educação do país modernizou os métodos sem a preocupação com seus respectivos referenciais teóricos, reafirmando uma formação apoiada na prática sem teoria, o que não permitia ao professor a construção de alternativas próprias para a educação brasileira, contradição evidenciada na formação do professor primário desde o início de nossa história.

Processava-se, desta forma, um modelo de formação voltado para a diretividade e o controle, sem espaço para a criatividade, para o espírito científico e para uma formação contextualizada e interdisciplinar que possibilitasse ao professor buscar alternativas compatíveis com as necessidades dos cidadãos, omitindo-se a análise dos problemas educacionais que são, em parte, gerados pelas contradições da sociedade de classes em que vivemos.

\section{Considerações finais}

Do estudo realizado, buscando compreender as implicações do capital na formação do professor primário no período em que a ideia de moderno começava a tomar vulto no país, afirma-se que a preocupação com a formação deste profissional esteve sempre ligada aos interesses da ordem capitalista dominante.

A década de 1920 representou um momento importante para o pais, tendo em vista que iniciava um processo que vai se acelerar na década de 1930, indicando uma ideia de mudança e de renovação, para o que a educação constituía uma exigência para a sociedade industrial que se buscava.

Neste prisma se incluem necessariamente os processos de educação inicial e continuada de professores que, ao longo de nossa história não evidenciaram características relativas aos aspectos técnicos, científicos e políticos, nem destacaram a relação entre escola e a sua realidade interna e externa, o que inviabilizava qualquer transformação significativa das instituições educativas, servindo apenas para treinamento da prática e aceitação passiva da nova ordem.

Ficava, assim, definida a educação voltada para o trabalho, deixando claro que, junto à formação para o exercício do magistério, o curso de formação de professores primários tinha, também, a incumbência de preparar pessoal para outras áreas profissionais requeridas na sociedade. Afinal, como diz Sodré (1977,p.72), se a necessidade maior era o número de operários, do que de intelectuais, "o esforço do Estado deveria ser muito maior em proporcionar aos capitalistas os proletários de que eles necessitavam".

Neste processo, a prática era a ordem e, assim, o "aprender fazendo" se constituía a profissionalização por excelência do professor primário, o que justificava a importância das "escolas-modelo" e das "escolas de aplicação, centro de treinamento para o "aprender a fazer".

Com esta preocupação, se criaram laboratórios, se instituíram cursos de férias para aperfeiçoamento contínuo aos professores em serviço, bem como à criação de gabinetes, laboratórios e museus como os de Física e Química, de Psicologia e Pedagogia. A isto, acrescem-se as medidas moralizadoras através da educação cívica a ser desenvolvida nas escolas, com obrigatoriedade. 
Assumia importância, nesta questão, a proposta das Ligas Nacionalistas de formação moral. A substância real do esforço, a real decolagem para a modernidade de fato alcançada, foi a difusão do regime disciplinar. Disto se depreende o caráter ambíguo das reformas educacionais dos anos vinte, visto que, ao mesmo tempo em que acolhia a ideia de mudança social pela mudança da educação, também buscava pela educação a manutenção da ordem existente que tinha no latifúndio a base de sustentação.

É uma prática que reproduzia os movimentos nacionalistas que, sem buscar solução própria e sem levantar uma oposição crítica ao atraso do país, afirmavam-se medidas para se encurtar as distâncias e adequar a realidade local aos modelos importados.

Para tanto, contribuiu o positivismo, pois tal como afirma Pesavento (1985,p.67), "a visão positivista era progressista e conservadora ao mesmo tempo" e, portanto, contraditória, enquanto pretendia "conciliar o progresso econômico com a conservação da ordem social".

Era necessário preparar a sociedade, através do professor, para a aceitação da nova ordem, para a disciplina necessária aos novos métodos de trabalho que a fábrica gerava, para a formação de atitudes compatíveis com a sociedade de consumo que se implantava. Esta situação parecia clara para governantes e reformadores, o que evidenciou as contradições e as tensões na formação docente naquele período.

Neste processo, substituía-se o conhecimento pelo procedimento eficaz traduzido nos métodos de ensino, o que integrava a modernização dos cursos de formação de professores à modernização desenraizada da sociedade que se manifestava nas modernas construções, nos meios de comunicação e de transporte e nos novos aparatos importados, do que pode-se afirmar que, a partir dos anos vinte, o processo de acumulação capitalista que foi se consolidando se traduziu na modernização do projeto educacional, tendo no curso normal a sua base de sustentação. Isto é a comprovação histórica mais evidente da subjugação da educação ao capital e, nela, a formação de professores.

\section{Referências}

ANTUNHA, Heládio César Gonçalves. A instrução pública no Estado de São Paulo: a Reforma de 1920. São Paulo: Faculdade de Educação, FEUSP. (Estudos e Documentos, 12), 1976.

ANUÁRIO ESTATÍSTICO DO BRASIL DO INSTITUTO NACIONAL DE ESTATÍSTICA (s.n). História da Educação no Brasil. Período Primeira República (1920-1929). Disponível em <http://www.pedagogiaemfoco.pro.br/heb06.htm\#texto>. Acesso em 20 de janeiro de 2014.

BASBAUM, Leôncio. História sincera da República- de 1889 a 1930. São Paulo: AlfaOmega, 1976.

BOLETIM DA ABE. Ano II, n. 6, julho de 1927. p. 1. Disponível em http://www.museudavida.fiocruz.br/brasiliana/cgi/cgilua.exe/sys/start.htm?infoid=2\&sid=15 Acesso em 25 de janeiro de 2014.

BUSATO, Ida Zanir Leite. Alegrete, o ensino e sua história. Alegrete/RS: AGE, 1983.

CARVALHO, Marta Maria Chagas de. Molde nacional e fôrma cívica. Tese de Doutorado. São Paulo: Faculdade de Educação da Universidade de São Paulo, 1986.

CARONE, Edgar. A república nova (1930-1937). São Paulo: Difusão Européia do Livro, 1974.

CHAUÍ, Marilena de Souza M. O que é ideologia? São Paulo: Brasiliense, 1980. 
CUNHA, Luiz Antônio. A universidade temporã. Rio de Janeiro: Francisco Alves,1986.

CUNHA, Célio da. Educação e autoritarismo no Estado Novo. São Paulo: Cortez, 1989.

DECCA, Edgar Salvadori. 1930: o silencio dos vencidos. São Paulo. Brasiliense. 1981.

HARDMAN, Francisco Foot. Trem fantasma: a modernidade na selva. São Paulo: Companhia das Letras, 1988

HILL, David. O neoliberalismo global, a resistência e a deformação da educação. In [S.I] Currículo sem Fronteiras, v.3, n.2. pp. 24-59. jul/dez, 2003. Disponível em: <http://www.curriculosemfronteiras.org.>. Acesso em 15 de março de 2015.

MARCUSE, Herbert. Razão e Revolução. Rio de Janeiro: Paz e Terra, 1978

MARX, KARL. Contribuição à crítica da economia política. Tradução e Introdução de Florestan Fernandes. 2a edição. São Paulo: Editora Expressão Popular, 2008.

MELlO, João Manuel Cardoso. O Capitalismo tardio. 21982. ed. São Paulo, Brasiliense.1982

MORAES, Maria Célia M. de. A via brasileira para o capitalismo: correlações de força e interesses fragmentados. (Relatório de Pesquisa, 1992). Niterói: Universidade Federal Fluminense, 1992.

MORAES, José Geraldo. Cidade e Cultura Urbana na Primeira República. São Paulo: Atual, 1994.

NAGLE, Jorge. Educação e sociedade na Primeira República. São Paulo: EPU- Rio de Janeiro, MEC,1974.

OLIVEIRA, Lucia Lippi de. A questão nacional na Primeira República. São Paulo: Brasiliense; Brasília: CNPq, 1990

PESAVENTO, Sandra Jatahy. História do Rio Grande do Sul. Porto Alegre: Mercado Aberto, 1985.

PRADO Junior, Caio. A Historia Econômica do Brasil. São Paulo. Brasiliense 2012.

REIS FILHO, Casemiro. A educação e a ilusão liberal. São Paulo: Cortez, 1981.

SAVIANI, Dermeval. Escola e democracia. São Paulo: Cortez, 1984.

SAVIANI, Dermeval. História Das Ideias Pedagógicas No Brasil. São Paulo: Autores Associados, 2008

SERVA, Mário Pinto. A União e a educação Nacional. I Conferencia nacional de Educação. Tese $n^{\circ}$ 103, Curitiba. I Conferência Nacional de Educação, Curitiba, 1927. pp. 642-648. Disponível em: file:///J:/I\%20CONFERENCIA\%20NACIONAL\%20DE\%20EDUCA\%C3\%87\%C3\%830\%2 01927.pdf. Acesso em março de 2015.

SERVA, Mário Pinto. A dinâmica da Educação Nacional. Revista Nacional de Educação. Rio de Janeiro: Ministério de Educação e Saúde Pública, n. 9, Junho, 1933. 
SEVCENKO, Nicolau. Orfeu extático na metrópole. São Paulo, sociedade e cultura nos frementes anos 20. São Paulo: Companhia das Letras, 1992.

SODRÉ, Nelson Werneck. Síntese da história da cultura brasileira. Rio de Janeiro: Civilização Brasileira, 1977.

\section{Legislação}

BRASIL. Constituição da República dos Estados Unidos do Brasil (24 de fevereiro de 1891) in Barreto, C. E.(org.). Constituições do Brasil, vol I, São Paulo: Edição Saraiva, 1971, pp. $104-171$.

BRASIL, MEC. Decreto Lei nº 7.566 de 23 de Setembro de 1909. Disponível em < http://portal.mec.gov.br/setec/arquivos/pdf3/decreto_7566_1909.pdf> Acesso em 20 de setembro de 2017.

MINAS GERAIS. Decreto $n$. 8.162 - de 20 de janeiro de 1928 - Aprova o regulamento do ensino nas Escolas Normais. Minas Gerais. Diário Oficial. Órgão Oficial dos Poderes do Estado. Ano XXXVII, n. 37, 1928.

MINAS GERAIS. Decreto 8.225 de 11 de fevereiro de 1928. Aprova os programas do ensino normal. Minas Gerais. Diário Oficial. Órgão Oficial dos Poderes do Estado. Ano XXXVII, n. 37, 1928.

RIO GRANDE DO SUL. Decreto n. 4277 de 13 de março de 1929 - regulamento do Ensino Normal do Estado do Rio Grande do Sul. Publicação da Secretaria do Interior. Porto Alegre: Oficinas Gráficas da Federação, 1929.

RIO GRANDE DO SUL. Decreto 3.898 de 4 de outubro de 1927. Expede novo regulamento da instrução pública. Palácio do Governo. Porto Alegre, 4/10/1927. Disponível em <https://repositorio.ufsc.br/xmlui/bitstream/handle/123456789/100089/dec_3898_1927.pdf?s equence=1\&isAllowed=y $>$ Acesso em 20 de setembro de 2016.

SÃO PAULO. Decreto n. 3.356 - de 31 de maio de 1921. Regulamenta a Lei 1750 de 8 de dezembro de 1920, que reforma a Instrução Pública. In Coleção das Leis e Decretos do Estado de São Paulo, Imprensa Oficial do Estado, Tomo XXXI. 1921, pp.64-133. 